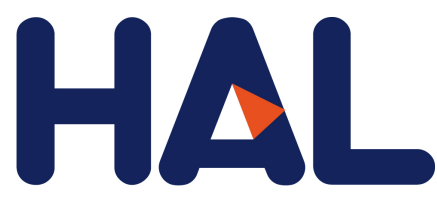

archives-ouvertes

\title{
When Traumatic event Exposure Characteristics Matter: Impact of Traumatic event Exposure Characteristics on Post-traumatic and Dissociative Symptoms.
}

\author{
Abdel Halim Boudoukha, Ornella Ouagazzal, Nelly Goutaudier
}

\section{To cite this version:}

Abdel Halim Boudoukha, Ornella Ouagazzal, Nelly Goutaudier. When Traumatic event Exposure Characteristics Matter: Impact of Traumatic event Exposure Characteristics on Post-traumatic and Dissociative Symptoms.. Psychological Trauma: Theory, Research, Pratice, and Policy, American Psychological Association, 2016. halshs-01902623

\section{HAL Id: halshs-01902623 \\ https://halshs.archives-ouvertes.fr/halshs-01902623}

Submitted on 2 Sep 2021

HAL is a multi-disciplinary open access archive for the deposit and dissemination of scientific research documents, whether they are published or not. The documents may come from teaching and research institutions in France or abroad, or from public or private research centers.
L'archive ouverte pluridisciplinaire HAL, est destinée au dépôt et à la diffusion de documents scientifiques de niveau recherche, publiés ou non, émanant des établissements d'enseignement et de recherche français ou étrangers, des laboratoires publics ou privés. 


\section{Psychological Trauma: Theory, Research, Practice, and Policy}

\section{When Traumatic Event Exposure Characteristics Matter: Impact of Traumatic Event Exposure Characteristics on Posttraumatic and Dissociative Symptoms}

Abdel H. Boudoukha, Ornella Ouagazzal, and Nelly Goutaudier

Online First Publication, December 8, 2016. http://dx.doi.org/10.1037/tra0000243

CITATION

Boudoukha, A. H., Ouagazzal, O., \& Goutaudier, N. (2016, December 8). When Traumatic Event Exposure Characteristics Matter: Impact of Traumatic Event Exposure Characteristics on Posttraumatic and Dissociative Symptoms. Psychological Trauma: Theory, Research, Practice, and Policy. Advance online publication. http://dx.doi.org/10.1037/tra0000243 


\title{
When Traumatic Event Exposure Characteristics Matter: Impact of Traumatic Event Exposure Characteristics on Posttraumatic and Dissociative Symptoms
}

\author{
Abdel H. Boudoukha and Ornella Ouagazzal \\ University of Nantes
}

\author{
Nelly Goutaudier \\ University of Poitiers
}

\begin{abstract}
Objective: Traumatic events can lead to posttraumatic (posttraumatic stress disorder [PTSD] specific symptoms) and dissociative symptoms (PTSD nonspecific symptoms). However, the trauma exposure characteristics (type of exposure, categorical form, number of exposures and the age of the exposure) are rarely studied. We hypothesized that the characteristics of a traumatic event are the only predictors of specific posttraumatic symptoms (intrusion, avoidance, negative cognitive impairment) and nonspecific symptoms (dissociation). We also hypothesized that some characteristics of a traumatic event are specific predictors of posttraumatic symptoms, whereas other characteristics are predictors of nonspecific symptoms. Method: Three hundred nine university students participated in the study (201 men, 108 women; mean age : 19.32 years). Students completed questionnaires assessing trauma exposure characteristics, PTSD, dissociation, and burnout. Multiple linear regressions were conducted to identify predictive factors for elevated specific PTSD symptoms and elevated nonspecific PTSD symptoms. Results: A different impact of the characteristics of 1 or more traumatic events was observed on specific posttraumatic symptoms. In men, the model was significant, with 6 predictors explaining $14 \%$ to $23 \%$ of the variance of specific posttraumatic symptoms. In women, 2 predictors explaining $15 \%$ to $28 \%$ of the variance of posttraumatic symptoms were found. The characteristics of the traumatic event were not the only predictors of posttraumatic symptoms (specific and nonspecific), with emotional exhaustion playing an unexpected predictive role. Conclusions: Burnout and PTSD might share emotional exhaustion as a common risk factor for PTSD. Further studies in this area are warranted, noteworthy focusing on clinical populations.
\end{abstract}

Keywords: trauma, PTSD, dissociation, risk factor, burnout

\begin{abstract}
A traumatic event refers to a situation of a sudden, brutal, and unusual exposure to a life-threatening or serious threat to one's physical integrity. There are four categories of traumatic event: disasters (natural disasters and those caused by humans), interpersonal violence (war situations, barbaric acts, physical and/or sexual assaults, fights with weapons, etc.), serious accidents, and the sudden death of a relative and/or close friend. Two concomitant (Criterion A1 and Criterion A2 from the DSM-IV-TR) have long characterized a traumatic event (American Psychiatric Association [APA], 2003). However, the fifth edition of the Diagnostic and Statistical Manual of Mental Disorders (DSM-5; APA, 2015) contains considerable changes. As subjective reactions have not been reported to be a strong predictor of posttraumatic stress disorder (PTSD) symptoms, intense emotional reaction (Criterion A2) has been removed (Friedman, Resick, Bryant, \& Brewin,
\end{abstract}

Abdel H. Boudoukha and Ornella Ouagazzal, Faculty of Psychology, University of Nantes; Nelly Goutaudier, Department of Psychology, University of Poitiers.

Correspondence concerning this article should be addressed to Abdel $\mathrm{H}$. Boudoukha, Faculté de Psychologie, Chemin de la Censive du Tertre, BP 81227-44312 Nantes Cedex 3, France. E-mail: abdel-halim.boudoukha@ univ-nantes.fr
2011; O’Donnell, Creamer, McFarlane, Silove, \& Bryant, 2010; Pereda \& Forero, 2012). Criterion A1 (Criterion $\mathrm{A}^{1}$ in the DSM5), a condition preceding the subsequent development of PTSD, has been expanded beyond (a) direct exposure and (b) indirect exposure, and now includes (c) direct vicarious exposure (directly learning that one or more traumatogenic events has happened to a relative and/or close friend), and (d) indirect vicarious chronic exposure, which is repeated indirect or extreme exposure to aversive-unpleasant elements or consequences of traumatogenic events, particularly in a professional context (APA, 2015).

Prevalence rates concerning exposure to traumatic events vary depending on the population. Although international studies estimate that $28.6 \%$ to $82.7 \%$ of individuals are exposed to one or more traumatic events during their life (Benjet et al., 2016), in France, the lifetime frequency of exposure to traumatic events is $72.7 \%$ (Husky, Lépine, Gasquet, \& Kovess-Masfety, 2015). This very high rate raises the central issue of potential, real psychopathological consequences.

Psychopathological reactions have preferentially been studied in trauma- and stressor-related disorders such as acute stress disorder or PTSD. In these cases, a traumatic event leads to classic or

\footnotetext{
${ }^{1}$ e.g., Criterion A of the DSM-5 is "Exposure to actual death or threat of death, serious injury or sexual violence" (APA, 2015).
} 
specific posttraumatic symptoms: (a) intrusive symptoms (i.e., the individual constantly reexperiences the event through flashbacks or nightmares), (b) avoidance symptoms (thoughts or behavior), and (c) negative alterations in cognitions and mood (APA, 2015). Among the intrusive symptoms, dissociation (i.e., memory loss in the recollection of certain aspects of the event, emotional and behavioral reexperiencing) or dissociative disorders are of prime importance (Wolf et al., 2012), as they are often activated as a result of a traumatic event, but are not specific to it. Thus, dissociative symptoms may be observed in other psychopathological disorders (Carlson, Dalenberg, \& McDade-Montez, 2012).

Risk factors for developing PTSD symptoms have been identified, such as environmental and demographic factors, personality and psychiatric history, dissociation, cognitive and biological systems, and genetic or familial risk (Breslau et al., 1998; Brewin, Andrews, \& Valentine, 2000; Ozer, Best, Lipsey, \& Weiss, 2003). Dissociation during the traumatic event and a history of trauma exposure have been shown to be the strongest predictors of the development of PTSD. Risk factors related to trauma exposure history have also been reported: (a) exposure prior to the focal trauma, (b) history of prior exposure to trauma or to chronic stress, particularly if it is experienced at a young age (Lyons-Ruth, Dutra, Schuder, \& Bianchi, 2006), and (c) type of prior trauma exposure, with prior assault being a particularly strong risk factor for the development of PTSD upon subsequent traumatization.

These findings are important in psychopathological research involving people exposed to one or more traumatic events. Although the specific characteristics of the event leading to the development of symptoms are very important, they are not sufficiently known. For instance, studies may focus on individuals exposed to a specific form of traumatic event (such as sexual assault, rape, or sexual abuse) or different forms of traumatic events (natural disasters and motor vehicle accidents [MVAs]; Benjet et al., 2016; Ehlers et al., 1998; Nishith, Nixon, \& Resick, 2005; Spinazzola et al., 2014). Nevertheless, factors regarding basic characteristics of traumatic events are more related to personal characteristics (e.g., age of the child) than the event-related characteristics. Actually, research is mainly based on one traumatic event (e.g., MVA) with one type exposure (e.g., direct exposure), without focusing on other types of exposure (e.g., indirect exposure to a motor vehicle accident). Although some types of exposure (direct exposure vs. indirect exposure) are considered, others are not taken into account (e.g., vicarious exposures; Frans, Rimmö, Aberg, \& Fredrikson, 2005; Shah, Garland, \& Katz, 2007). Finally, samples are composed of individuals who have experienced several traumatic events and participants who have experienced only one (Belleville, Marchand, St-Hilaire, Martin, \& Silva, 2012; White et al., 2015). As a consequence, our research aims to identify the different types of events and the different types of exposure at the same time, which is rare in the literature, and their effects on PTSD and dissociative symptoms. The central question of the specification of the characteristics of the traumatic events, and their impact on posttraumatic and dissociative symptoms, is also considered.

The aim of this study is to investigate the impact of traumatic exposure characteristics (type of exposure, categorical form, number of exposures, and the age of the exposure) on posttraumatic and dissociative symptoms. We made the assumption that the characteristics of a traumatic event would be predictors of specific posttraumatic symptoms (intrusion, avoidance, negative cognitive impairment) and nonspecific dissociative symptoms. We also hypothesized that some characteristics of a traumatic event would be specific predictors of posttraumatic symptoms, whereas other characteristics are predictors of nonspecific symptoms.

\section{Method}

\section{Participants}

Three hundred nine university students in the department of Sciences and Techniques of Physical and Sports Activities (Nantes, France) agreed to participate in the study. The sample included 201 men and 108 women, with an average age of 19.32 years $(S D=1.75)$. Students were divided depending on their level of study (293 undergraduate students and 18 master's students), their family situation (165 students [53.40\%] were single and 144 [46.60\%] were in a relationship), and their lifestyle (112 students [36.20\%] lived with their parents, 105 [34\%] lived in apartments, 43 students [13\%] lived with a roommate, and 49 [15.90\%] lived on the university campus).

They all participated voluntarily and were not remunerated for this study. Written informed consent was obtained from all participants.

\section{Procedure}

The study followed the ethical guidelines of the Helsinki declaration (Word Medical Association, 2013). The ethical guidelines set out by the University of Nantes for the conduct of research on human subjects do not require that research on students be approved by an institutional review board. Nevertheless, the ethical aspects of all research on students were carefully considered by the faculty and students prior to the beginning of the study. Students were approached in their academic department, and the questionnaires to complete were provided (a) in their classroom following the agreement of the director, and (b) during a lecture. The questionnaires took $15 \mathrm{~min}$ to complete and two investigators signed the questionnaire record. Anonymity of students was guaranteed.

\section{Measures}

Traumatic events. Traumatic events were assessed using the Inventory of Traumatic Events (Ouagazzal, Boudoukha, \& Thomas-Ollivier, 2015). This is a self-report inventory with a list of 27 traumatic events categorized and differentiated into four forms of exposure (direct, indirect, direct vicarious, and indirect vicarious chronic exposure). The inventory specifies the number of events, date(s) of occurrence, and the intensity of the distress(es) experienced. For each traumatic event, respondents have to check the box(es) corresponding to the form of exposure and indicate the number of exposures and the approximate date(s) of the occurrence of the event.

Dissociative symptoms. Dissociative symptoms were assessed using the 28-item self-report French version of the Dissociative Experiences Scale (DES; Darves-Bornoz, Degiovanni, \& Gaillard, 1999). Individuals indicate, on a scale of 100, the percentage of time they felt the emotions or behaviors listed. Thus, the score ranges from $0 \%$ to $100 \%$, and there are 10 possible answers. 
To obtain a total score, scores of each item were added and divided by 28. A threshold score of 25 was determined as an indicator of dissociative disorders. The factor analysis of the French version of the DES revealed three factors: (a) Depersonalization and Derealization, (b) Dissociative Amnesia, and (c) Absorption and Imaginative Capacity. In addition, the reliability of the French version of the DES in this population was high, with a coefficient of 0.89 for the first factor, 0.86 for the second factor, and 0.81 for the third factor.

Posttraumatic stress symptoms. Posttraumatic stress symptoms were assessed using the French version of the Impact of Event Scale-Revised (IES-R; Brunet, St-Hilaire, Jehel, \& King, 2003) and the French version of the Post-Traumatic Check List Scale (PCL-S; Yao, Cottraux, Note, de Mey-Guillard, \& Ventureyra, 2003). The IES-R measures the severity of posttraumatic symptoms. It consists of 22 items assessing symptoms of intrusion, avoidance, and hyperarousal regarding a dangerous and threatening event. Answers are rated on a Likert-type scale from 0 (none) to 4 (extremely). Three subscales correspond to Intrusion, Avoidance, and Hyperarousal. The total score ranges from 0 to 88 and a threshold score was set at 33 . The French version of the IES-R has good internal consistency, with consistency coefficients ranging from 0.81 to 0.93 for the three subscales and total score, and satisfactory test-retest reliability with Cronbach's alpha coefficients ranging from 0.71 to 0.76 for the three subscales and total score. The French version of PCL-S (Yao et al., 2003) is a self-report questionnaire measuring three sets of symptoms of PTSD and their severity. Answers are rated on a Likert scale from 1 (not at all) to 5 (very often). Participants have to evaluate the intensity of the traumatic event described in the last month. Three subscales correspond to the three components of PTSD according to the fourth edition of the DSM (APA, 1996): (a) Repetition, (b) Avoidance, and (c) Autonomic Hyperactivity. A cutoff score of 44 has been identified as indicating PTSD.

Student burnout. Student burnout was assessed using the French Student Version of the Maslach Burnout Inventory (Faye Dumanget, Le Borgne, \& Boudoukha, 2015), a 15-item self-report questionnaire divided into three subscales: Emotional Exhaustion, Cynicism, and Academic Efficiency. Students have to indicate the frequency of each item on a Likert scale ranging from 1 (never) to 6 (always). There is no overall score or clinical threshold. However, high scores on the subscales Emotional Exhaustion and Cynicism and low scores on Academic Efficiency indicated the presence of burnout symptoms (Schaufeli, Martinez, Marques Pinto, Salanova, \& Bakker, 2002).

\section{Statistical Analyses}

Statistical analyses were performed with SPSS Version 22 (IBM software). Descriptive statistics were initially performed, and then multiple linear regressions were conducted according to our objective, that is, to identify predictive factors for elevated specific PTSD symptoms (i.e., intrusion, avoidance, negative alterations) and elevated nonspecific PTSD symptoms (i.e., dissociative symptoms). Statistical predictors tested (independent variables) were sociodemographic variables (e.g., gender, age) and trauma-related variables (e.g., type and number of traumatic exposures). The significance level was set at 0.05 (two-tailed).

\section{Results}

\section{Traumatic Events and Symptoms}

Descriptive analyses indicated the range of exposure to traumatic events in our sample (see Table 1). Given the mean age of our population, exposures to traumatic events mostly occurred during adolescence. The heterogeneity of the exposures in our sample explains the overdispersion. Regarding specific and nonspecific posttraumatic stress symptoms, our participants reported levels below the threshold scores for the three measures used (see Table 2). Scores on the three dimensions of academic burnout were nonpathological.

\section{Impact of Traumatic Events}

We made the assumption that the characteristics of the traumatic event are the only predictors of specific and nonspecific posttraumatic symptoms. The multiple regression analysis conducted did not confirm our hypothesis (see Tables 3 and 4). Indeed, besides the characteristics of one or more traumatic events, some dimensions of burnout (emotional exhaustion) and sociodemographic characteristics (family situation and level of education) were also predictors for the intensity of posttraumatic symptoms.

Table 1

Means and Standard Deviations of the Number of Traumatic Events and Age of Their Occurrence Depending on the Category of the Traumatic Event and the Forms of Exposure

\begin{tabular}{|c|c|c|c|c|c|}
\hline \multirow[b]{2}{*}{$\begin{array}{l}\text { Categories of } \\
\text { traumatic events }\end{array}$} & \multicolumn{4}{|c|}{ Forms of exposure } & \multirow[b]{2}{*}{$\begin{array}{l}\text { Age (years) mean } \\
\text { (standard deviation) }\end{array}$} \\
\hline & $\begin{array}{c}\text { Direct exposure } \\
\text { number mean } \\
\text { (standard deviation) }\end{array}$ & $\begin{array}{c}\text { Indirect exposure } \\
\text { number mean } \\
\text { (standard deviation) }\end{array}$ & $\begin{array}{l}\text { Direct vicarious } \\
\text { exposure number } \\
\text { mean (standard } \\
\text { deviation) }\end{array}$ & $\begin{array}{l}\text { Indirect vicarious } \\
\text { chronic exposure } \\
\text { number mean } \\
\text { (standard deviation) }\end{array}$ & \\
\hline Disasters & $.61(.83)$ & $.31(.63)$ & $.70(1.00)$ & $.15(.58)$ & $13.18(4.26)$ \\
\hline Sexual assaults & $.03(.19)$ & $.02(.16)$ & $.23(.54)$ & $.07(.32)$ & $16.53(3.90)$ \\
\hline Nonsexual assaults & $.34(.56)$ & $.32(.64)$ & $.41(.75)$ & $.10(.44)$ & $16.38(4.12)$ \\
\hline Accidents & $.48(.63)$ & $.35(.65)$ & $.56(.77)$ & $.07(.30)$ & $16.14(3.94)$ \\
\hline Death & $.02(.15)$ & $.40(.69)$ & $.74(.98)$ & $.10(.46)$ & $15.40(3.75)$ \\
\hline
\end{tabular}


Table 2

Descriptive Statistics of the Characteristics of the Symptomatology $(N=309)$

\begin{tabular}{|c|c|c|c|c|c|}
\hline $\begin{array}{l}\text { Specific and non specific } \\
\text { symptoms }\end{array}$ & Variables & $\begin{array}{c}\text { General } \\
\text { Mean and } \\
\text { standard } \\
\text { deviation }(\mu)\end{array}$ & $\begin{array}{c}\text { Minimum to } \\
\text { Maximum } \\
\text { (threshold values) }\end{array}$ & $\begin{array}{c}\text { Men } \\
\text { Mean and } \\
\text { standard } \\
\text { deviation }(\mu)\end{array}$ & $\begin{array}{l}\text { Women } \\
\text { Mean and } \\
\text { standard } \\
\text { deviation }(\mu)\end{array}$ \\
\hline $\begin{array}{l}\text { Specific posttraumatic } \\
\text { symptoms measured } \\
\text { with the IES-R }\end{array}$ & $\begin{array}{l}\text { Intrusion } \\
\text { Avoidance } \\
\text { Hypervigilance } \\
\text { IES-R total score }\end{array}$ & $\begin{array}{c}11.33(7.68) \\
10.38(6.82) \\
5.21(5.04) \\
26.76(17.64)\end{array}$ & $\begin{array}{l}0 \text { to } 30 \\
0 \text { to } 27 \\
0 \text { to } 20 \\
0 \text { to } 72(33)\end{array}$ & $\begin{array}{r}10.23(7.50) \\
9.47(6.74) \\
4.37(4.67) \\
24.07(16.79)\end{array}$ & $\begin{array}{c}13.46(7.60) \\
12.14(6.65) \\
6.79(5.38) \\
31.85(18.15)\end{array}$ \\
\hline $\begin{array}{l}\text { Specific posttraumatic } \\
\text { symptoms measured } \\
\text { with the PCL-S }\end{array}$ & $\begin{array}{l}\text { Repetition } \\
\text { Avoidance } \\
\text { Hyperactivity } \\
\text { PCL-S total score }\end{array}$ & $\begin{array}{r}9.57(3.93) \\
12.98(5.52) \\
9.08(4.31) \\
31.62(12.11)\end{array}$ & $\begin{array}{l}5 \text { to } 25 \\
7 \text { to } 30 \\
5 \text { to } 24 \\
17 \text { to } 74(44)\end{array}$ & $\begin{array}{r}8.78(3.67) \\
11.97(4.82) \\
8.24(3.74) \\
28.98(10.60)\end{array}$ & $\begin{array}{l}10.96(4.00) \\
14.78(6.22) \\
10.58(4.84) \\
36.32(13.21)\end{array}$ \\
\hline $\begin{array}{l}\text { Nonspecific posttraumatic } \\
\text { symptoms (dissociation) } \\
\text { measured with the DES }\end{array}$ & $\begin{array}{l}\text { DES total score } \\
\text { Amnesia } \\
\text { Depersonalization } \\
\text { Absorption }\end{array}$ & $\begin{array}{l}20.34(11.80) \\
13.02(10.47) \\
20.76(12.43) \\
33.26(18.83)\end{array}$ & $\begin{array}{c}1.07 \text { to } 64.29(25) \\
0 \text { to } 53.64 \\
.91 \text { to } 73.64 \\
0 \text { to } 86.67\end{array}$ & $\begin{array}{l}19.13(11.64) \\
11.94(10.06) \\
19.93(12.47) \\
31.34(18.66)\end{array}$ & $\begin{array}{l}22.50(11.84) \\
14.97(10.95) \\
22.26(12.27) \\
36.76(18.73)\end{array}$ \\
\hline $\begin{array}{l}\text { Academic burnout } \\
\text { measured with the } \\
\text { MBI-SS }\end{array}$ & $\begin{array}{l}\text { Emotional exhaustion } \\
\text { Cynicism } \\
\text { Academic efficiency }\end{array}$ & $\begin{array}{r}13.36(4.76) \\
8.01(3.91) \\
22.58(4.56)\end{array}$ & $\begin{array}{c}5 \text { to } 27(14,1) \\
3 \text { to } 22(13,9) \\
13 \text { to } 36(18,83)\end{array}$ & $\begin{array}{r}12.66(4.43) \\
8.06(3.63) \\
22.69(4.77)\end{array}$ & $\begin{array}{r}14.67(5.08) \\
7.93(4.39) \\
22.37(4.14)\end{array}$ \\
\hline
\end{tabular}

Note. $\quad$ IES-R = Impact of Event Scale-Revised; PCL-S = Post-Traumatic Check List Scale; DES = Dissociative Experiences Scale; MBI-SS = Maslach Burn-out Inventory - Student Survey.

\section{Differentiation of Predictors of Specific and Nonspecific Posttraumatic Symptoms}

Predictors of specific posttraumatic symptoms. A multiple regression analysis was performed independently for each gender (see Table 3). A different impact of the characteristics of one or more traumatic events was observed on specific posttraumatic symptoms. In men, the model tested was significant, with six predictors explaining $14 \%$ to $23 \%$ of the variance of specific posttraumatic symptoms. The predictors related to the characteristics of the event include the number of exposures to death and the age of exposure, exposure to natural disasters, experienced as a witness (indirect), or experienced via a relative (indirect vicarious). Among the other predictors, being single and the emotional exhaustion dimension of burnout were significant predictors.

In women, two predictors explaining $15 \%$ to $28 \%$ of the variance of posttraumatic symptoms (see Table 3) were identified. Regarding characteristics of the event, direct exposure to sexual violence was a significant predictor. As far as "uncharacteristic of the event" is

Table 3

Results of Multiple Linear Regression Analyses Predicting the Intensity of Classic Posttraumatic Stress Symptoms by Gender

\begin{tabular}{lcc}
\hline \multicolumn{1}{c}{ Predictors } & $\begin{array}{c}\text { Men Beta } \\
(B)\end{array}$ & $\begin{array}{c}\text { Women Beta } \\
(B)\end{array}$ \\
\hline $\begin{array}{l}\text { Number of exposures to one or } \\
\text { more deaths }\end{array}$ & $.20^{*}$ & \\
Indirect exposure to disasters & $.19^{*}$ & \\
Indirect vicarious exposure to & $.16^{*}$ to .18 & \\
$\quad$ disasters & $-.15^{*}$ & \\
Mean age at exposure to death & $.14^{*}$ & $.21^{*}$ to $.35^{*}$ \\
Family situation & $.24^{*}$ to $.34^{*}$ & $.23^{*}$ \\
Emotional exhaustion & & \\
Direct exposure to sexual assault & &
\end{tabular}

$* p<.05$. concerned, the emotional exhaustion dimension of burnout was the only significant predictor.

Emotional exhaustion ( $\beta=0.21$ to 0.35 ; see Table 3 ) was the strongest significant predictor of the intensity of posttraumatic symptoms.

Predictors of nonspecific symptoms (dissociation). A different impact of the characteristics of one or more traumatic events on nonspecific posttraumatic symptoms was observed (see Table 4). In men, the model is significant, with three predictors explaining $15 \%$ to $27 \%$ of the variance of dissociative symptoms (see Table 2). Direct exposure to accidents was a predictor related to the characteristic of the event, and predictors related to "uncharacteristic of the event" included the level of education and the emotional exhaustion dimension of burnout.

In women, three predictors explaining $25 \%$ to $46 \%$ of the variance of dissociative symptoms were identified (see Table 4 ). The predictors related to the characteristics of the event were direct exposure to sexual violence and indirect exposure to disasters. The predictor related to "uncharacteristic of the event" was the emotional exhaustion dimension of burnout.

Table 4

Results of Multiple Linear Regression Analyses Predicting the Intensity of Dissociative Symptoms by Gender

\begin{tabular}{lcc}
\hline \multicolumn{1}{c}{ Predictors } & $\begin{array}{c}\text { Men Beta } \\
(\beta)\end{array}$ & $\begin{array}{c}\text { Women Beta } \\
(\beta)\end{array}$ \\
\hline Direct exposure to accidents & $.15^{*}$ & \\
Level of study & $-.17^{*}$ & \\
Emotional exhaustion & $.21^{*}$ to $.27^{*}$ & $.37^{*}$ to $.46^{*}$ \\
Direct exposure to sexual assault & & $.28^{*}$ \\
Indirect exposure to disasters & & $.25^{*}$ \\
\hline
\end{tabular}

\footnotetext{
$* p<.05$.
} 
These results indicate that emotional exhaustion $(B=0.21$ to 0.46 ; see Table 4) was the strongest significant predictor for dissociative symptoms.

\section{Discussion}

This study aimed to highlight the psychopathological impact of traumatic events. The characteristics of the traumatic event were not the only predictors of posttraumatic symptoms (specific and nonspecific), with emotional exhaustion playing an unexpected predictive role, leading to a twofold discussion. The first part of the discussion focuses on emotional exhaustion, which appears to be a significant predictor regardless of gender, and the second part focuses on the gender difference regarding the characteristics of the traumatic event.

\section{Burnout: A Transdiagnostic Predictor?}

Emotional exhaustion, as a moderating variable, was the strongest predictor of posttraumatic and dissociative symptoms. The presence of emotional exhaustion (a subdimension of burnout) as a predictor of the intensity of specific and nonspecific posttraumatic symptoms questions the relationship between PTSD and burnout. The developmental psychopathology perspective (Bosma, 2006) and the key concept known as multifinality nature might be useful in understanding the role of emotional exhaustion in PTSD. Multifinality nature refers to the concept that during development, different psychopathological states (burnout, adjustment disorder, PTSD, etc.) might be generated by a single common vulnerability factor. Development then depends on the effects of other factors. Our findings suggest that a traumatic event might generate PTSD among students who have previously presented emotional exhaustion. This interpretation is in line with studies suggesting that emotional exhaustion is a risk factor for posttraumatic stress (Boudoukha, Altintas, Rusinek, Fantini-Hauwel, \& Hautekeete, 2013; Boudoukha, Hautekeete, Abdelaoui, Groux, \& Garay, 2011). Unlike the categorical approach, this perspective promotes a transdiagnostic approach, considering that different psychopathological disorders share common and/or similar psychological processes (cognitive, behavioral, and emotional; Brown \& Barlow, 2005). This approach allows differentiation of the psychological processes involved in the demonstration, development, and maintenance of psychopathological dysfunction. Thus, burnout and PTSD share a common vulnerability factor: emotional exhaustion. It is independent of other factors, such as the characteristics of a particular traumatogenic event and gender.

\section{Differential Impact of Traumatogenic Events Between Men and Women}

Multiple regression analyses indicated gender differences in psychopathological impact of the characteristics of traumatic events. In men, the number of exposures to death and age of exposure, as well as the indirect or direct vicarious exposure to natural disasters, were significant predictors of the intensity of posttraumatic symptoms. Direct exposure to accidents was a significant predictor of dissociative symptoms. In women, direct exposure to sexual violence was a significant predictor of posttraumatic symptoms, and indirect exposure to catastrophes was a significant predictor of dissociative symptoms. Gender differences regarding exposure to traumatic events are consistent with current research (Ehring, Razik, \& Emmelkamp,
2011; Frans et al., 2005; Galovski, Blain, Chappuis, \& Fletcher, 2013; Weissman et al., 2005). Several interpretations have been proposed to explain these discrepancies. Compared with women, men are more likely to engage themselves in risky behaviors and therefore are more at risk for exposure to accidents or disasters. However, women are more likely to be exposed to recurrent physical and/or sexual assault (Galovski et al., 2013; Stein, Walker, \& Forde, 2000). Finally, as they use coping strategies less adapted for dealing with a traumatogenic event, women are more at risk regardless of the characteristics of the traumatogenic event (Schmied et al., 2015).

It is important to note that our participants were young and had no specific posttraumatic symptoms, which could be considered as an important limitation and may explain the low variance in the models.

\section{Conclusion}

Our findings highlighted the impact of the characteristics of traumatic events on posttraumatic and dissociative symptoms. Given that few studies have controlled for the characteristics of the traumatic event, our study has an original aspect. Our findings show that emotional exhaustion (a subdimension of burnout) is the strongest predictor of posttraumatic and dissociative symptoms. We therefore believe that burnout and PTSD share emotional exhaustion as a common vulnerability factor. A longitudinal study aiming to differentiate the effect of traumatic events among people with burnout may clarify the role of emotional exhaustion as a transdiagnostic process. Differentiation in the impact of characteristics of traumatic events in men and women was also observed, suggesting different risk factors depending on gender. These results might help clinicians to determine an appropriate treatment based on the characteristics of trauma exposure and gender. Further studies focusing on clinical populations that have been exposed to one or more traumatic events are warranted.

\section{References}

American Psychiatric Association. (1996). DSM-IV: Manuel diagnostique et statistique des troubles mentaux (4th ed.) [Diagnostic and Statistical Manual of Mental Disorders]. Paris, France: Masson.

American Psychiatric Association. (2003). DSM-IV-TR: Manuel diagnostique et statistique des troubles mentaux (4th ed., text. rev.) [Diagnostic and Statistical Manual of Mental Disorders]. Paris, France: Masson.

American Psychiatric Association. (2015). DSM-5: Manuel diagnostique et statistique des troubles mentaux (5th ed.) [Diagnostic and Statistical Manual of Mental Disorders]. Paris, France: Masson.

Belleville, G., Marchand, A., St-Hilaire, M.-H., Martin, M., \& Silva, C. (2012). PTSD and depression following armed robbery: Patterns of appearance and impact on absenteeism and use of health care services. Journal of Traumatic Stress, 25, 465-468. http://dx.doi.org/10.1002/jts.21726

Benjet, C., Bromet, E., Karam, E. G., Kessler, R. C., McLaughlin, K. A., Ruscio, A. M., . . . Koenen, K. C. (2016). The epidemiology of traumatic event exposure worldwide: Results from the World Mental Health Survey Consortium. Psychological Medicine, 46, 327-343. http://dx.doi.org/10 .1017/S0033291715001981

Bosma, H. A. (2006). Introduction à la psychopathologie développementale [An introduction to developmental psychopathology]. Orientation Scolaire et Professionnelle, 35, 251-268. http://dx.doi.org/10.4000/osp.1097

Boudoukha, A. H., Altintas, E., Rusinek, S., Fantini-Hauwel, C., \& Hautekeete, M. (2013). Inmates-to-staff assaults, PTSD and burnout: Profiles of risk and vulnerability. Journal of Interpersonal Violence, 28, 2332-2350. http://dx.doi.org/10.1177/0886260512475314

Boudoukha, A. H., Hautekeete, M., Abdelaoui, S., Groux, W., \& Garay, D. (2011). Burnout et victimisations: Effets des agressions des personnes 
détenues envers les personnels de surveillance [Burnout and victimisation: Impact of inmates' aggression towards prison guards]. L'Encéphale, 37, 284-292. http://dx.doi.org/10.1016/j.encep.2010.08.006

Breslau, N., Kessler, R. C., Chilcoat, H. D., Schultz, L. R., Davis, G. C., \& Andreski, P. (1998). Trauma and posttraumatic stress disorder in the community: The 1996 Detroit Area Survey of Trauma. Archives of General Psychiatry, 55, 626-632. http://dx.doi.org/10.1001/archpsyc.55.7.626

Brewin, C. R., Andrews, B., \& Valentine, J. D. (2000). Meta-analysis of risk factors for posttraumatic stress disorder in trauma-exposed adults. Journal of Consulting and Clinical Psychology, 68, 748-766. http://dx.doi.org/10 .1037/0022-006X.68.5.748

Brown, T. A., \& Barlow, D. H. (2005). Dimensional versus categorical classification of mental disorders in the fifth edition of the Diagnostic and Statistical Manual of Mental Disorders and beyond: Comment on the special section. Journal of Abnormal Psychology, 114, 551-556.

Brunet, A., St-Hilaire, A., Jehel, L., \& King, S. (2003). Validation of a French version of the impact of event scale-revised. The Canadian Journal of Psychiatry, 48, 56-61.

Carlson, E. B., Dalenberg, C., \& McDade-Montez, E. (2012). Dissociation in posttraumatic stress disorder Part I: Definitions and review of research. Psychological Trauma: Theory, Research, Practice, and Policy, 4, 479489. http://dx.doi.org/10.1037/a0027748

Darves-Bornoz, J. M., Degiovanni, A., \& Gaillard, P. (1999). Validation of a French version of the Dissociative Experiences Scale in a rape-victim population. The Canadian Journal of Psychiatry, 44, 271-275.

Ehlers, A., Clark, D. M., Dunmore, E., Jaycox, L., Meadows, E., \& Foa, E. B. (1998). Predicting response to exposure treatment in PTSD: The role of mental defeat and alienation. Journal of Traumatic Stress, 11, 457-471. http://dx.doi.org/10.1023/A:1024448511504

Ehring, T., Razik, S., \& Emmelkamp, P. M. (2011). Prevalence and predictors of posttraumatic stress disorder, anxiety, depression, and burnout in Pakistani earthquake recovery workers. Psychiatry Research, 185, 161-166. http://dx.doi.org/10.1016/j.psychres.2009.10.018

Faye Dumanget, C., Le Borgne, M., \& Boudoukha, A. H. (2015, May). Validation en français de l'échelle Maslach Burnout Inventory-Student Survey $(M B I-S S)$ [French validation of the MBI-SS]. Paper presented at the 1st french-speaking colloque, retour sur les processus thérapie comportementale et cognitive (back to the CBT process), Lyon, France.

Frans, O., Rimmö, P.-A., Aberg, L., \& Fredrikson, M. (2005). Trauma exposure and post-traumatic stress disorder in the general population. Acta Psychiatrica Scandinavica, 111, 291-299. http://dx.doi.org/10.1111/j.16000447.2004.00463.x

Friedman, M. J., Resick, P. A., Bryant, R. A., \& Brewin, C. R. (2011). Considering PTSD for DSM-5. Depression and Anxiety, 28, 750-769. http://dx.doi.org/10.1002/da.20767

Galovski, T. E., Blain, L. M., Chappuis, C., \& Fletcher, T. (2013). Sex differences in recovery from PTSD in male and female interpersonal assault survivors. Behaviour Research and Therapy, 51, 247-255. http://dx.doi.org/ 10.1016/j.brat.2013.02.002

Husky, M. M., Lépine, J.-P., Gasquet, I., \& Kovess-Masfety, V. (2015). Exposure to traumatic events and posttraumatic stress disorder in France: Results from the WMH survey. Journal of Traumatic Stress, 28, 275-282. http://dx.doi.org/10.1002/jts. 22020

Lyons-Ruth, K., Dutra, L., Schuder, M. R., \& Bianchi, I. (2006). From infant attachment disorganization to adult dissociation: Relational adaptations or traumatic experiences? Psychiatric Clinics of North America, 29, 63-86, viii. http://dx.doi.org/10.1016/j.psc.2005.10.011

Nishith, P., Nixon, R. D. V., \& Resick, P. A. (2005). Resolution of trauma-related guilt following treatment of PTSD in female rape victims: A result of cognitive processing therapy targeting comorbid depression? Journal of Affective Disorders, 86, 259-265. http://dx.doi.org/ 10.1016/j.jad.2005.02.013
O’Donnell, M. L., Creamer, M., McFarlane, A. C., Silove, D., \& Bryant, R. A. (2010). Should A2 be a diagnostic requirement for posttraumatic stress disorder in DSM-V? Psychiatry Research, 176, 257-260. http:// dx.doi.org/10.1016/j.psychres.2009.05.012

Ouagazzal, O., Boudoukha, A. H., \& Thomas-Ollivier, V. (2015). Etude de l'Impact Différencié des Evénements Traumatiques sur les Symptômes Dissociatifs et Post-Traumatiques [Differential Impact of traumatic events on dissociative and post-traumatic symptoms]. Paper presened at the 43rd Congrès Annuel de l'Association Française de Thérapie Cognitive et Comportementale, Paris, France.

Ozer, E. J., Best, S. R., Lipsey, T. L., \& Weiss, D. S. (2003). Predictors of posttraumatic stress disorder and symptoms in adults: A meta-analysis. Psychological Bulletin, 129, 52-73. http://dx.doi.org/10.1037/0033-2909 .129 .1 .52

Pereda, N., \& Forero, C. G. (2012). Contribution of criterion A2 to PTSD screening in the presence of traumatic events. Journal of Traumatic Stress, 25, 587-591. http://dx.doi.org/10.1002/jts.21736

Schaufeli, W. B., Martinez, I. M., Pinto, A. M., Salanova, M., \& Bakker, A. B. (2002). Burnout and engagement in university students: A cross-national study. Journal of Cross-Cultural Psychology, 33, 464-481. http://dx.doi .org/10.1177/0022022102033005003

Schmied, E. A., Padilla, G. A., Thomsen, C. J., Lauby, M. D. H., Harris, E., \& Taylor, M. K. (2015). Sex differences in coping strategies in military survival school. Journal of Anxiety Disorders, 29, 7-13. http://dx.doi.org/ 10.1016/j.janxdis.2014.10.005

Shah, S. A., Garland, E., \& Katz, C. (2007). Secondary traumatic stress: Prevalence in humanitarian aid workers in India. Traumatology, 13, 59-70. http://dx.doi.org/10.1177/1534765607299910

Spinazzola, J., Hodgdon, H., Liang, L.-J., Ford, J. D., Layne, C. M., Pynoos, R., ... Kisiel, C. (2014). Unseen wounds: The contribution of psychological maltreatment to child and adolescent mental health and risk outcomes. Psychological Trauma: Theory, Research, Practice, and Policy, 6(Suppl. 1), S18-S28. http://dx.doi.org/10.1037/a0037766

Stein, M. B., Walker, J. R., \& Forde, D. R. (2000). Gender differences in susceptibility to posttraumatic stress disorder. Behaviour Research and Therapy, 38, 619-628. http://dx.doi.org/10.1016/S0005-7967(99) 00098-4

Weissman, M. M., Neria, Y., Das, A., Feder, A., Blanco, C., Lantigua, R., . . Olfson, M. (2005). Gender differences in posttraumatic stress disorder among primary care patients after the World Trade Center attack of September 11, 2001. Gender Medicine, 2, 76-87. http://dx.doi .org/10.1016/S1550-8579(05)80014-2

White, J., Pearce, J., Morrison, S., Dunstan, F., Bisson, J. I., \& Fone, D. L. (2015). Risk of post-traumatic stress disorder following traumatic events in a community sample. Epidemiology and Psychiatric Sciences, 24, 249-257. http://dx.doi.org/10.1017/S2045796014000110

Wolf, E. J., Miller, M. W., Reardon, A. F., Ryabchenko, K. A., Castillo, D., \& Freund, R. (2012). A latent class analysis of dissociation and posttraumatic stress disorder: Evidence for a dissociative subtype. Archives of General Psychiatry, 69, 698-705. http://dx.doi.org/10.1001/ archgenpsychiatry.2011.1574

Word Medical Association (WMA). (2013). WMA Declaration of Helsinki Ethical Principles for Medical Research Involving Human Subjects. JAMA, 310, 2191-2194. http://dx.doi.org/10.1001/jama.2013.281053

Yao, S.-N., Cottraux, J., Note, I., de Mey-Guillard, C., \& Ventureyra, V. (2003). Évaluation des états de stress post-traumatique: validation d'une échelle, la PCLS [Post-traumatic stress disorder assessment: French validation of the PCLS]. L'Encéphale: Revue de psychiatrie clinique biologique et thérapeutique, 29, 232-238.

Received May 30, 2016

Revision received October 26, 2016

Accepted November 7, 2016 